\title{
Long-acting formulations delivering aripiprazole: beyond single-value characterizations of steady- state pharmacokinetics
}

This article was published in the following Dove Press journal:

Neuropsychiatric Disease and Treatment

I2 July 2017

Number of times this article has been viewed

\author{
Scott A McConnell' \\ Dharmik N Desai' \\ Sejal P Faldu' \\ Marjie L Hard ${ }^{2}$ \\ Angela Y Wehr ${ }^{3}$ \\ Peter J Weiden' \\ Lisa von Moltke ${ }^{3}$
}

'Medical Affairs, Alkermes, Inc., Waltham, MA, ${ }^{2}$ Nuventra Pharma Sciences, Durham, NC, ${ }^{3}$ Clinical Research, Alkermes, Inc., Waltham, MA, USA
Correspondence: Lisa von Moltke Alkermes, Inc., 852 Winter Street, Waltham, MA, 0245I, USA

$\mathrm{Tel}+$ | 78| 609607 |

Email lisa.vonmoltke@alkermes.com

\section{Dear editor}

The recent publication by Salzman et $\mathrm{al}^{1}$ compared pharmacokinetic (PK) data from population PK (popPK) models for two long-acting antipsychotic formulations: aripiprazole once-monthly $400 \mathrm{mg}$ (AOM 400) and aripiprazole lauroxil (AL). We would like to address a few major concerns. The AL popPK model has been well described in a peer-reviewed publication. ${ }^{2}$ However, Salzman et al omitted publishing information regarding the development and validation of the AOM popPK model, including any critical discussion of the covariates, other key characteristics, assumptions and limitations of the AOM model. Thus, a reader cannot objectively assess the simulated values for AOM reported in the publication.

In addition, the authors compared simulations from these two popPK models and focused only on selected PK parameters: the steady-state exposures $\left(\mathrm{C}_{\text {avg,ss }}\right.$ and $\left.\mathrm{C}_{\text {min,ss }}\right)$. With the statement, "At least half of the observed aripiprazole $\mathrm{C}_{\text {min,ss }}$ for AL $441 \mathrm{mg}$ were below the median $\mathrm{C}_{\text {min,ss }}$ for oral aripiprazole $10 \mathrm{mg}$ daily," the authors seem to imply that the median minimum plasma concentration of $94 \mathrm{ng} / \mathrm{mL}$, which results from the lowest effective dose of oral aripiprazole (10 mg daily), is a necessary threshold for efficacy, rather than a summary PK value. By definition of the term "median", half of the minimum plasma concentration values for the $10 \mathrm{mg}$ oral aripiprazole dose would also fall below $94 \mathrm{ng} / \mathrm{mL}$. More importantly, the efficacy of AL $441 \mathrm{mg}$ every 4 weeks, with its associated PK profile, was established in a Phase III study. ${ }^{3}$ Focusing on a single median steady-state exposure value ignores the intricacies of the entire PK profile and does not contribute to an understanding of overall clinical effectiveness.

The entire aripiprazole concentration-time curve following the administration of $\mathrm{AL}$ provides a complete and more meaningful view of the AL PK profile. The prodrug formulation of AL enables sustained release of aripiprazole with consistent drug levels maintained over the dosing interval. ${ }^{2}$ The PK profile of AOM $400 \mathrm{mg}$, however, is different, with peak-trough fluctuations as shown in Figure $1{ }^{4}$ The half-life of AL doses ranges from 53.9 days to 57.2 days, while the half-life of AOM 400 is 46.5 days. ${ }^{5,6}$ Thus, the PK profiles of $882 \mathrm{mg}$ every 4 weeks and AOM $400 \mathrm{mg}$ are not equivalent. These contrasting PK profiles have clinical implications including different dosing intervals and missed dose recommendations for AOM and AL. ${ }^{5,6}$

In summary, the efficacy of AL $441 \mathrm{mg}$ and $882 \mathrm{mg}$ dosed every 4 weeks has been demonstrated, with the $882 \mathrm{mg}$ dose offering higher exposures than $441 \mathrm{mg}$. All AL doses exhibit stable exposures over the 4-6-week dosing intervals and offer clinicians 


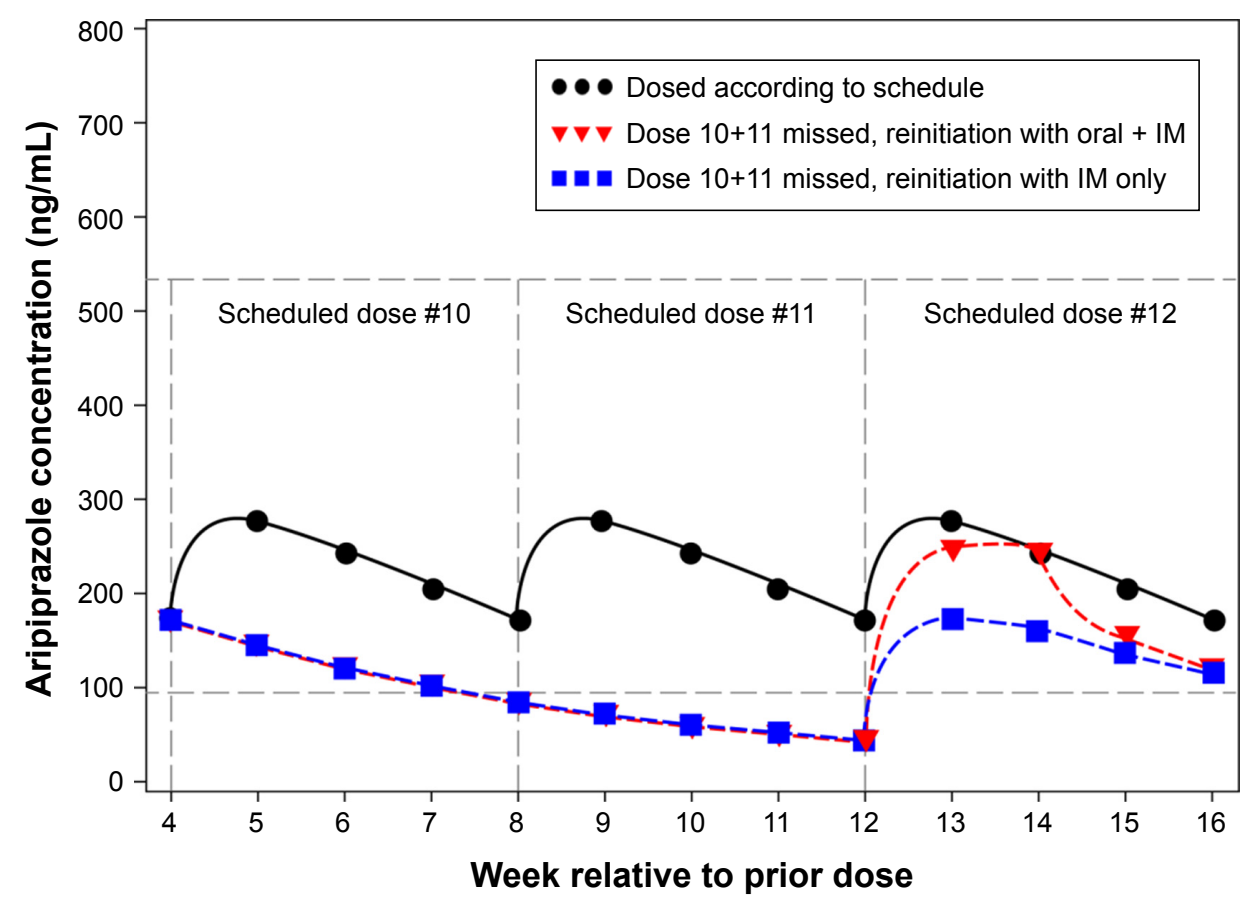

Figure I Simulated median aripiprazole concentrations for AOM $400 \mathrm{mg}$ at steady state (black circles) and missed doses with reinitiation (red triangles and blue squares). Notes: Dashed lines represent the upper and lower boundary of therapeutic window for aripiprazole determined in AOM PK studies. Reproduced from Center for Drug Evaluation and Research. Application Number: 20297IOrig/s000. Clinical Pharmacology and Biopharmaceutics Review(s). Silver Spring, MD: US Food and Drug Administration; $2013 .^{4}$

Abbreviations: AOM, aripiprazole once-monthly; IM, intramuscular; PK, pharmacokinetic.

multiple exposure options to match patients' individual treatment needs.

\section{Disclosure}

All of the authors are current or former employees of Alkermes, Inc. and MLH is an employee of Nuventra Pharma Sciences. The authors report no other conflicts of interest in this communication.

\section{References}

1. Salzman PM, Raoufinia A, Legacy S, Such P, Eramo A. Plasma concentrations and dosing of 2 long-acting injectable formulations of aripiprazole. Neuropsychiatr Dis Treat. 2017;13:1125-1129.
2. Hard ML, Mills RJ, Sadler BM, Turncliff RZ, Citrome L. Aripiprazole lauroxil: pharmacokinetic profile of this long-acting injectable antipsychotic in persons with schizophrenia. J Clin Psychopharmacol. 2017;37(3):289-295.

3. Meltzer HY, Risinger R, Nasrallah HA, et al. A randomized, doubleblind, placebo-controlled trial of aripiprazole lauroxil in acute exacerbation of schizophrenia. J Clin Psychiatry. 2015;76(8):1085-1090.

4. Center for Drug Evaluation and Research. Application Number: 202971Orig1s000. Clinical Pharmacology and Biopharmaceutics Review(s). Silver Spring, MD: US Food and Drug Administration; 2013.

5. ABILIFY MAINTENA® [prescribing information]. Tokyo, Japan: Otsuka Pharmaceutical Co., Ltd.; 2017.

6. ARISTADA ${ }^{\circledR}[$ prescribing information]. Waltham, MA: Alkermes, Inc.; 2017.

Dove Medical Press encourages responsible, free and frank academic debate. The content of the Neuropsychiatric Disease and Treatment 'letters to the editor' section does not necessarily represent the views of Dove Medical Press, its officers, agents, employees, related entities or the Neuropsychiatric Disease and Treatment editors. While all reasonable steps have been taken to confirm the content of each letter, Dove Medical Press accepts no liability in respect of the content of any letter, nor is it responsible for the content and accuracy of any letter to the editor.

\section{Publish your work in this journal}

Neuropsychiatric Disease and Treatment is an international, peerreviewed journal of clinical therapeutics and pharmacology focusing on concise rapid reporting of clinical or pre-clinical studies on a range of neuropsychiatric and neurological disorders. This journal is indexed on PubMed Central, the 'PsycINFO' database and CAS, and is the official journal of The International Neuropsychiatric Association (INA). The manuscript management system is completely online and includes a very quick and fair peer-review system, which is all easy to use. Visit http://www.dovepress.com/testimonials.php to read real quotes from published authors. 